\title{
An Epidemiological Analysis of Maxillofacial Fractures in the Inner Aegean Region: A Retrospective Evaluation of 343 Cases
}

\author{
Anvar Ahmedov ${ }^{1}$ (D) Muhammet Fatih Topuz ${ }^{2}$ (1) \\ ${ }^{1}$ Istanbul Başakşehir "Çam ve Sakura" City Hospital, Clinic of Plastic, Reconstructive and Aesthetic Surgery, Istanbul, Turkey \\ ${ }^{2}$ Kütahya University of Health Science, Faculty of Medicine, Department of Otolaryngology, Evliya Çelebi Training and Research Hospital, Kütahya, Turkey
}

ORCID ID: A.A. 0000-0002-5100-4672; M.F.T. 0000-0002-7996-662X

Citation: Ahmedov A, Topuz MF. An epidemiological analysis of maxillofacial fractures in the inner aegean region: A retrospective evaluation of 343 cases. Tr-ENT 2021;31(3):70-74. https://doi.org/10.26650/Tr-ENT.2021.1004133

ABSTRACT

Objective: The focus of this study was the sociocultural, economic, educational, and geographical factors that influence the incidence and types of fractures in maxillofacial trauma (MFT). The aim of this study was to identify the etiology and demographic characteristics of MFT cases in the inner (eastern) Aegean region.

Materials and Methods: The records of patients treated at the Kütahya Health Sciences University Evliya Çelebi Education and Research Hospital for MFT from January 1, 2017 to March 1, 2020 were analyzed retrospectively.

Results: A total of 476 bone fractures in 343 patients were analyzed. The sample comprised 239 male patients and 104 female patients. The average age was $35.19 \pm 17.79$ years. Traffic accidents were found to be the most common cause (42\%) of MFT. Of the isolated non-nasal bone fractures, 19 were in the maxilla, 17 in the zygoma, 14 in the mandible, and 7 in the frontal sinus. Nasal fractures (42.6\%) were found to be the most frequently occurring breakages. Surgery was performed in $35.27 \%$ of the patients who agreed to have surgery for MFT.

Conclusion: The etiology and incidence of MFT can vary not only by country but also by geographical region within countries. The results of this study support this view. A review of the literature indicated that MFT in the inner (eastern) Aegean region in Turkey has not yet been studied. Societal differences must be considered in the recommendation of measures to reduce the incidence of MFT and thus morbidity and mortality.

Keywords: Maxillofacial fracture, trauma, etiology

\section{INTRODUCTION}

In emergency medicine, maxillofacial trauma (MFT) is an important and frequently encountered health problem that usually requires a multidisciplinary approach. According to the World Health Organization, one person dies every 9 seconds because of severe MFT and the related complications (1). Nasal fractures are the most common facial fractures resulting from MFT, and mandible fractures are the second most common (2). The causes of MFT are, in descending order, traffic accidents, assaults, and falls. The ranking of these three etiologies is associated with sociocultural and socioeconomic factors. Assault was found to be the most common reason for MFT in developed societies, and traffic accidents were the most common reason in developing societies (3). In a Toronto-based study, assault was identified as the most common reason independent of gender. Traffic accidents were found to be the most common reason in a Tehran-based study $(2,3)$.

Anamnesis, physical examinations, and tomography (direct radiography and computed tomography) are the three main steps in diagnosis and treatment. The indications for surgery to treat trauma are based on these findings $(4,5)$. Besides having cosmetic problems, most of these patients have functional disorders, such as long-term eye and smell impairments, chewing problems, and breathing difficulties $(6,7)$. Therefore, the treatment of MFT patients should include the correction of not only potential functional defects but also cosmetic defects because deformities can cause severe psychological problems.

The study aimed to analyze the diagnosis and follow-up processes for patients with MFT. The demographic and clinical features of patients treated at the Kütahya Health Sciences

Corresponding Author: Anvar Ahmedov E-mail: anvar.ahmedov@yahoo.com

Submitted: 04.10.2021 • Accepted: 11.10.2021 • Published Online: 26.10.2021

This work is licensed under Creative Commons Attribution-NonCommercial 4.0 International License. 
University Evliya Çelebi Education and Research Hospital from January 1, 2017 to March 1, 2020 were evaluated.

\section{MATERIALS AND METHODS}

This study was conducted with the permission of the Kütahya University of Health Sciences ethics committee dated 26/06/2020 (2020/10-20). In this investigation, the Helsinki Declaration guidelines were followed.

The files of patients who were treated for MFT at the Kütahya Health Sciences University Evliya Çelebi Education and Research Hospital from January 1, 2017 to March 1, 2020 were analyzed retrospectively. The following patient data were considered: demographics (e.g., age, gender, and etiology), diagnosis, diagnostic radiological evaluations of bone fractures and the localization of traumatic fractures, treatment methods, and complications.

MFT patients with only superficial skin lacerations or with no pathology other than soft tissue injury were excluded from the study. In addition, patients whose essential data could not be obtained from the records were not included. The data were evaluated and descriptive statistics (means, minimum-maximum values, and standard deviations) were used for the continuous variables. Frequencies and percentages were used for the categorical variables. The chi-square test was used to determine the relationships between the groups and categorical variables. A value of $p<0.05$ was considered statistically significant.

\section{RESULTS}

The study evaluated 343 patients with an MFT diagnosis, there were 239 male and 104 female patients. The average age was $35.19 \pm 17.79$ years, and the period reviewed was January 1 , 2017 to March 1, 2020. Traffic accidents (42\%) were found to be the most common cause of MFT. The etiological distribution is summarized in Table 1.

Table 1: Etiological distribution of maxillofacial trauma

\begin{tabular}{lcc}
\hline & $\begin{array}{c}\text { Number of } \\
\text { patients }(\boldsymbol{n})\end{array}$ & $\begin{array}{c}\text { Percentage } \\
\text { (\%) }\end{array}$ \\
\hline Traffic accident & 144 & 42 \\
Fall & 85 & 24.7 \\
Assault & 52 & 15.2 \\
Work accident & 37 & 10.8 \\
Non-car traffic accident & 16 & 4.7 \\
(bicycle/motorcycle) & & \\
Animal kick & 5 & 1.5 \\
Firearm injury & 4 & 1.1 \\
Total & 343 & 100 \\
\hline
\end{tabular}

A total of 476 bone fractures were evaluated in 343 patients. When we examine the distribution of bone fractures, nasal fractures (42.6\%) were most frequent. Zygoma (25\%) and maxillary fractures (16\%) were highest in the distribution of bone fractures due to MFT without isolated nasal fracture.

Table 2 summarizes the distribution of bone fractures in MFT.

Table 2: Distribution of bone fractures caused by maxillofacial trauma

\begin{tabular}{|c|c|c|}
\hline & $\begin{array}{l}\text { Number of } \\
\text { patients }(n)\end{array}$ & $\begin{array}{c}\text { Percentage } \\
(\%)\end{array}$ \\
\hline Nasal bone & 203 & 42.6 \\
\hline Zygoma & 119 & 25 \\
\hline Inferior orbital rim & 44 & 37 \\
\hline Zygomatic arc & 53 & 44.5 \\
\hline Orbital base & 19 & 16 \\
\hline Tripod & 3 & 2.5 \\
\hline Maxilla & 76 & 16 \\
\hline Maxilla front wall & 69 & 90.7 \\
\hline Alveolus & 5 & 6.5 \\
\hline Le Fort I & 2 & 2.8 \\
\hline Mandibula & 68 & 14.3 \\
\hline Angulus & 17 & 25 \\
\hline Parasymphysis & 12 & 17.6 \\
\hline Corpus & 10 & 14.8 \\
\hline Subcondyle & 6 & 8.7 \\
\hline Alveolus & 6 & 8.7 \\
\hline Condyle & 5 & 7.4 \\
\hline Ramus & 5 & 7.4 \\
\hline Symphysis & 5 & 7.4 \\
\hline Coronoid process & 2 & 3 \\
\hline Frontal sinus front wall & 10 & 2.1 \\
\hline Total & 476 & 100 \\
\hline
\end{tabular}

Some patients had multiple fractures.

Of the patients with isolated non-nasal fracture MFT, 57 had a fracture on the right side of the face, and 62 had a fracture on the left side. Twenty-one patients had fractures on both sides of the face. Of the fractures classified as both isolated and multiple, 57 patients were observed to have only one bone fracture. Of the isolated bone fractures, 19 were in the maxilla, 17 in the zygoma, 14 in the mandible, and 7 in the frontal sinus.

When we examine the fractures according to their etiology, it was observed that the patients who had been involved in a traffic accident had a zygoma and mandible fracture, and patients who had been involved in a work accident mostly had a fracture in the mandible. Parasymphysis is the localization of the mandible fracture, which is seen most after a traffic accident and the corpus is seen most after a work accident. Zygoma fractures are seen as a result of assault and falling, and maxillary bone fracture in cases of gunshot injury.

The distribution of zygoma fractures showed that the zygomatic arch was the most common site (44.5\%), and the orbital rim was the second most common (Table 2). Maxillary bone fracture (38 patients) was the most common with zygoma fracture. In the zygomatic arch, non-displaced and displaced fractures without the collapse of the malar region and displaced fractures with the collapse of the malar region were seen. In two patients with 
an isolated collapse of the zygomatic arch, the Gillies approach was used for reduction. The transoral Keen approach was used in zygomatic arch reduction in five patients with combined fractures.

The maxilla fractures were primarily anterior maxillary sinus fractures. Five patients had alveolar process fractures, and two had Le Fort I fractures. Isolated maxillary bone fractures were diagnosed in 20 patients. In addition, maxillary bone fractures were seen in 38 patients, and coexisting zygomatic bone fractures were also detected. In 10 patients, the fracture line had passed through the infraorbital foramen and damaged the infraorbital nerve. In these patients, the nerve was relieved by the administration of neurolysis to the infraorbital nerve.

In this series, 68 mandible fractures were diagnosed in 41 patients. Twenty-seven of the patients had fractures in only the mandibular bone, and 14 had fractures in the mandibular and other facial bones. In 14 of the cases with isolated mandible fractures (Figure 1), a single fracture line was seen in the mandible; 13 had complex mandible fractures. The ranking on the basis of the localization of the mandible fractures indicated that the angulus (25\%) was the most common site (Table 2). Fractures of the mandibular condyle were treated with intermaxillary fixation. For the reduction of displaced segments of the mandibula and the achievement of precise occlusion in multiple fractures, an arch bar and cerclage wire were applied before rigid fixation was performed. The patients with mandibular fractures were required to wear face-lifting masks to provide external support for the bone and to restrict movement. Five patients who underwent surgery developed occlusion disorders. In one patient, an orocutaneous fistula developed, and in another, plate screw exposure in the parasymphysis occurred. None of the patients had facial nerve parasites. The damaged mandibular nerve in two patients, mental nerve in one patient, and marginal mandibular nerve in one patient were repaired.

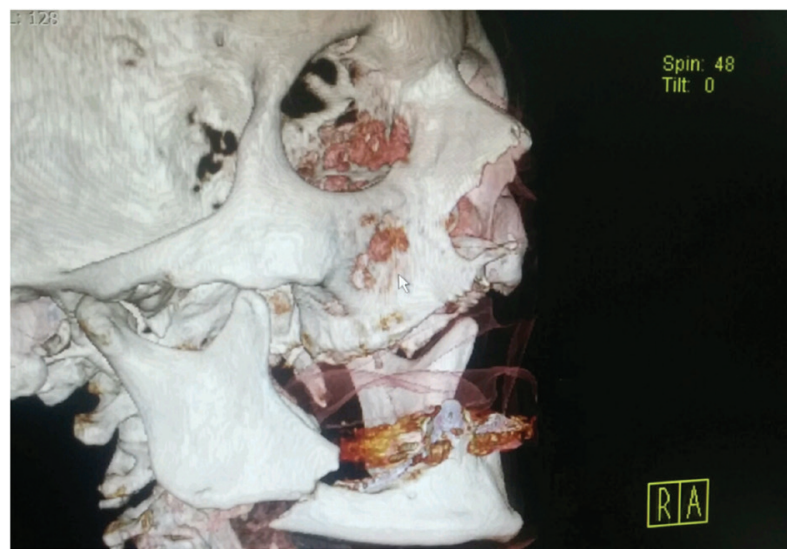

Figure 1: Patient's isolated mandibular corpus fracture

In this study, seven of the 10 frontal sinus fractures were isolated fractures. Surgical interventions were not carried out in the cases where the patients had not been affected aesthetically. Reduction and microplate and screw fixation were used in the open frontal sinus and anterior wall fractures. They were also used in clean lacerations on the forehead. Alloplastic materials were not used in dirty injuries. The temporal muscle or dermo-fascial flap from the area adjacent to the collapsed area was transposed onto the collapsed area for aesthetic alignment, and the flap was used as an awning.

Surgical intervention was performed under general anesthesia in 121 patients in our cases. Of these, 76 were due to nasal bone fracture, while 45 patients were due to other MFT. The reduction was performed under local anesthesia due to isolated nasal fracture in 44 patients. While 46 patients did not agree to surgical intervention, 132 patients were not planned for surgery.

\section{DISCUSSION}

Patient age and gender, the incidence of MFT, the etiology and distribution of the fractures by bone have been associated with socioeconomic, cultural, educational, and geographical factors (9). A review of the literature indicated that the most common etiologies were traffic accidents, assaults, and falls (9). Traffic accidents were the most frequent cause of MFT in developing countries, and assaults were the most common reason in developed countries. However, sports injuries were also a frequent cause of MFT in societies in which sports such as rugby were popular (10). In Şanlıurfa, traffic accidents were the most frequent reason for falls $(3,9,11)$. In this study, traffic accidents accounted for almost half (42\%) of the MFT cases. Falls were the next most frequently occurring reason, followed by violence.

MFT can occur at any age; however, in our study $50 \%$ of the patients were aged 15 to 45 years (12). Similar rates (60.7\%) were found in previous studies. The incidence of MFT in the pediatric age group has been reported to be $5 \%$ (13), Bamjee et al. (14) reported this rate as $8 \%$. The most frequent causes were attacks and firearm injuries. Unlike the findings of studies in other countries, those from the studies conducted in Turkey (Gönüllü et al.) indicated rates of pediatric cases as high as $33.7 \%$ (9). These patients had most frequently reported falls and traffic accidents. In this study, the rate of pediatric patients was found to be $13.1 \%$, and the etiological distribution of the patients was found to be traffic accidents and assaults. Twenty-eight patients were over the age of 65. As was found in previous studies, falls were the most common etiology in geriatric patients.

The incidence of MFT is higher in men than in women. In a study conducted at Osaka University in 2001, lida et al. reported the male-female ratio as 2.8:1 (15). In their study based in Van in 2009, Kırış et al. found that $73.9 \%$ of the MFT patients were male (16). In their 2008 study in Ankara, Demir et al. found that the male-female ratio was 2.8:1 (3). The findings of this study were similar to those of previous studies. The male-female ratio was $2.3: 1$. This was slightly lower than the previously reported rate. This difference was attributed to higher numbers of female drivers and increased participation in business and social life. 
As Topuz (17) and Hwang et al. (18) stated, due to its anatomical structure and protruding location, the most common facial fractures in this study were found to be nasal fractures (42.6\%). The most common causes of nasal bone fractures are: traffic accidents, falls, exposure to physical violence, work accidents, and sports injuries (17). In this study, the most common causes were traffic accidents (46.2\%). When isolated nasal fractures were not considered, there were differences in the most commonly reported facial bone fracture associated with MFT. Schaftenaar et al. (19) and Bamjee et al. (14) reported that the most common fractures were in the mandibular. Afzelius et al. (20) and Bernstein (21) reported that zygoma and maxilla fractures were the most common. An examination of studies conducted in Turkey indicated that the most common types of mandibular fractures found in the 2,901 disease series in Diyarbakır, the Elazig-Sivas- and Sanliurfa-based studies, and the Van (province)-centered study were maxilla fractures $(9-11,22,23)$.

In the present study, which was based in Kütahya, the zygomatic bone was the most common site in multiple fracture cases, and in isolated non-nasal fractures, single bone fractures were found in the maxillary bone. The zygoma fractures were caused primarily by trauma. The zygoma is a strong bone, however, its protruding structure and the relative weakness of the adjacent bones make it vulnerable to trauma.

Although most studies have found the mandibular to be the most common site of facial bone fractures, these injuries were the fourth most frequent type in this study. Mandibular fractures can have multiple etiologies, however, they develop especially after been struck. In the present study, the rates of mandibular fractures were lower than those in previous studies because only a relatively small number of MFT patients had experienced assaults. The mandible, which is U-shaped, can be divided into nine anatomical regions. Frontal impacts can cause fractures in the symphysis, condyle, and angulus. Impacts to the mental or corpus region can cause subcondylar fractures (24). In addition, there is an anatomical weakness in the third molar tooth-bound angulus region (24). Fractures have most frequently been observed in the condyle, corpus, and angulus (24) Kırış et al. (16) found that the parasymphysis was the most common fracture site. The findings of the present study confirmed those of previous studies regarding the angulus as the most common fracture area.

Frontal sinus fractures constitute $5 \%$ to $12 \%$ of all facial bone fractures (25). Because of trauma-related edema, the fracture can be detected only by examination and tomography. Rodriguez et al. (26) found frontal sinus fractures, fractures, brain injuries, shock, and comas in $75 \%$ of high-energy trauma cases. Schults et al. (25) treated frontal sinus anterior wall contour disorders and moderate collapse fractures with fillers. They reported that interventions were not required because the frontal sinus in pediatric patients is not well developed. Kim et al. (27) discussed the potentially fatal complications that can result from frontal sinus fractures. They asserted that moderate and advanced aesthetic appearance disorders that occur after a fracture can be treated with local or free flaps and alloplastic materials.

The treatment protocol for MFT is the reduction of bone fragments, correction of occlusions, stabilization of broken bones, and achievement of functional and aesthetically acceptable improvements. Dimitroulis et al. (28) reported that $57 \%$ of MFT cases received treatment. Gönüllü et al. (9) performed surgery on $25 \%$ of maxilla fractures, $44.3 \%$ of zygoma fractures, and $64.5 \%$ of mandible fractures. Forty-five patients in the present study underwent surgical interventions; 10 patients did not agree to this treatment. Surgery was not planned for 85 patients. Of the patients who accepted surgery as an MFT treatment option, 35\% received surgical interventions.

MFT has a multifaceted etiology that is influenced by socioeconomic, cultural, and geographical factors. A review of the literature revealed epidemiological differences not only by country but also by region within countries. The first study examining MFT patients in the Aegean region, which we can find in the literature, was the study Aydın-based 63 diseases Illkören et al. (29). However, this study examined only patients with mandible fractures. The present study is very valuable because of the high frequency and epidemiological distribution of MFT cases in the Aegean region.

The most important limitation of our study is that patients with isolated non-displaced nasal fractures and patients who do not want to undergo intervention despite having a displaced fracture generally do not apply to ENT/Plastic surgeons after admission to the emergency department. Therefore, nasal fracture rates were lower than we expected. It is thought that the number of patients with isolated alveolar fractures is relatively low due to the fact that patients with isolated alveolar fractures are referred to dentists for treatment.

Most had received dental referrals. MFT is often seen in multi trauma, such as that caused by traffic accidents. The primary evaluation of vital functions is a more accurate approach to the treatment of severe trauma. Unfortunately, some of these patients died at the time of trauma during the first intervention or even without intervention; thus, MFT-related departments cannot be consulted. Therefore, these patients could not be included in the study.

\section{CONCLUSION}

A majority of MFT cases require hospital admission. Epidemiological studies can contribute to the identification of measures to reduce the incidence of trauma in geographically and socioeconomically diverse regions.

Ethics Committee Approval: This study was conducted with the permission of the Kütahya University of Health Sciences ethics committee dated 26/06/2020 (2020/10-20). In this investigation, the Helsinki Declaration guidelines were followed.

Informed Consent: Written informed consent was obtained. 
Peer-Review: Externally peer-reviewed.

Author Contributions: Conception/Design of Study- A.A.; Data Acquisition- M.F.T.; Data Analysis/Interpretation- A.A., M.F.T.; Drafting Manuscript- A.A., M.F.T.; Critical Revision of Manuscript- A.A., M.F.T.; Final Approval and Accountability- A.A., M.F.T.

Conflict of Interest: Authors declared no conflict of interest.

Financial Disclosure: Authors declared no financial support

\section{REFERENCES}

1. Tokat T. Maxillofacial trauma. IN: Müderris T, Muz SE, Kesici GG, İslamoğlu Y editors. Basic approach and management of otorhinolaryngology. Academician bookstore 2019; Chapter 103, pp 889-901.

2. Zargar M, Khaji A, Karbakhsh M, Zarei MR. Epidemiology study of facial injuries during a 13 month of trauma registry in Tehran. Indian J Med Sci 2004;58(3):109-14.

3. Demir Z, Öktem F, Velidedeoglu H, Çelebioğlu S. Evaluation of 121 cases with maxillofacial fracture and comparison with the literature. KBB - Forum 2008;7(3):85-90.

4. Sojot AJ, Meisami T, Sandor GK, Clokie CM. The epidemiology of mandibular fractures treated at the Toronto general hospital: A review of 246 cases. J Can Dent Assoc 2001;67(11):640-4.

5. Carlin CB, Ruff G, Mansfeld CP, Clinton MS. Facial fractures and related injuries: a ten-year retrospective analysis. J Craniomaxillofac Trauma 1998;4(2):44-3.

6. Kırış M, Yuca K, Çelebi S, Kıroğlu F, Çankaya H. Our treatment approach in maxillofacial fractures: retrospective review. Türkiye Klinikleri J Med Sci 2009;29(3):696-701.

7. Gassner R, Tuli T, Hächl O, Rudisch A, Ulmer H. Craniomaxillofacialtrauma: a 10 year review of 9,543 cases with 21,067 injuries. J Craniomaxillofac Surg 2003;31(1):51-61.

8. Kim JJ, Huoh K. Maxillofacial (midface) fractures. Neuroimaging Clin N Am 2010;20(4):581-96.

9. Gönüllü H, Karadaş S, Işık D, Kocak ÖF, Tekin H. Maxillofacial Trauma Cases Applying To An Emergency Service: A Retrospective Study. Turk Plast Surg 2011;19(3):121-4.

10. Esen A, Isık K. Etiology of Maxillofacial Injuries Observed in Our Country and Report of Two Cases. ADO Journal of Clinical Sciences 2013;6(4):1329-35.

11. Gürger M., Ateşçelik M. Epidemiological features of maxillofacial traumas presenting to the emergency department. JAEM 2012;11:98-101.

12. O'Connor RC, Shakib K, Brennan PA. Recent advances in the management of oral and maxillofacial trauma. Br J Oral Maxillofac Surg 2015;53(10):913-21.
13. Lee WT, Koltai PJ. Nasal deformity in neonates and young children. Pediatr Clin North Am 2003;50(2):459-67.

14. Bamjee $Y$, Lownie JF, Cleaton-Jones PE, Lownie MA. Maxillofacial injuries in a group of South Africans under 18 years of age. $\mathrm{Br} J$ Oral Maxillofac Surg 1996;34(4):298-302.

15. lida S, Kogo M, Sugiura T, Mima T, Matsuya T. Retrospective analysis of 1502 patients with facial fractures. Int J Oral Maxillofac Surg 2001;30(4):286-90.

16. Kırış M, Yuca K, Çelebi S, Kıroğlu F, Çankaya H. Treatment Modalities in Maxillofacial Fractures: Retrospective Analysis. Türkiye Klinikleri J Med Sci 2009;29(3):696-701.

17. Topuz MF, Tok Umay S, Oghan F, Musmul A, Erdogan O, Kutuk SG. Investigation of the effectiveness of physical examination and radiologıcal imaging methods in the diagnosis of nasal bone fractures. Annals of Medical Research 2021;27(7):1913-7.

18. Hwang K, You SH. Analysis of facial bone fractures: An 11-year study of 2,094 patients. Indian J Plast Surg 2010;43(1):42-8.

19. Schaftenaar E, Bastiaens GJ, Simon EN, Merkx MA. Presentation and management of maxillofacial trauma in Dar es Salaam, Tanzania. East Afr Med J 2009;86(6):254-8.

20. Afzelius LE, Rosén C. Facial fractures. A review of 368 cases. Int J Oral Surg 1980;9(1):25-32.

21. Bernstein MP. The Imaging of Maxillofacial Trauma 2017. Neuroimaging Clin N Am 2018;28(3):509-24.

22. Erol B, Tanrikulu R, Görgün B. Maxillofacial fractures. Analysis of demographic distribution and treatment in 2901 patients (25-year experience). J Craniomaxillofac Surg 2004;32(5):308-13.

23. Bozkuş F, lynen $I$, Şan $I$. Retrospective analysis of the patients with maxillofacial traumas. Journal of Medical Research 2011;9(1):10-6.

24. Demirdöver C, Şahin B, Ataseven M, Özkan HS, Öztan HY. Retrospective Analysis of 124 Mandible Fracture Cases who have been operated In one year. Turk Plast Surg 2009;17(3):145-8.

25. Schultz K, Braun TL, Truong TA. Frontal Sinus Fractures. Seminars Plast Surg 2017;31(2):80-4.

26. Rodriguez ED, Stanwix MG, Nam AJ, et al. Twenty-six-year experience treating frontal sinüs fractures: a novel algorithm based on anatomical fracture pattern and failure of conventional techniques. Plast Reconstr Surg 2008;122(6):1850-66.

27. Kim YW, Lee DH, Cheon YW. Secondary Reconstruction of Frontal Sinus Fracture. Arch Craniofac Surg 2016;17(3):103-10.

28. Dimitroulis G, Eyre J. A 7-year review of maxillofacial trauma in a central London hospital. Br Dent J 1991;170(8):300-2.

29. Illkören Sahin NS, Bulut B, Sonel AM, Ceyan E. Retrospective analysis of 63 mandible fracture cases operated within three years. Journal of ADÜ Faculty of Medicine 2011;12:1-4. 